\title{
Use of Batch Mixing To Investigate the Continuous Solvent-Free Mechanical Synthesis of OLED Materials by Twin-Screw Extrusion (TSE)
}

\author{
Deborah E. Crawford, ${ }^{*}+\odot$ Stuart L. James, ${ }^{\dagger}$ and Tony McNally, ${ }^{*}+$
}

${ }^{\dagger}$ School of Chemistry and Chemical Engineering, Queen’s University Belfast, David Keir Building, 39-123 Stranmillis Road, Belfast BT9 5AG, Northern Ireland

${ }^{\ddagger}$ International Institute for Nanocomposite Manufacturing (IINM), WMG, University of Warwick, Coventry CV4 7AL, United

Kingdom

\section{Supporting Information}

ABSTRACT: Mechanochemical synthesis has the potential to change the way in which chemistry is conducted, particularly with regard to removing or dramatically reducing the need for solvents. Recently, it has been demonstrated that mechanochemistry can be carried out continuously and on large scale through the use of twin-screw extrusion (TSE). TSE has successfully been

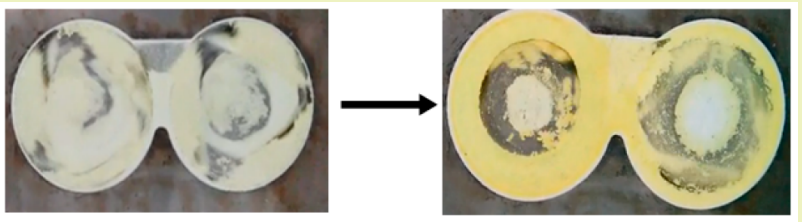
applied to the synthesis of cocrystals, metal organic frameworks (MOFs), deep eutectic solvents (DESs), metal complexes, and organic condensation reactions. However, while TSE provides a route for mechanochemical synthesis to be developed into a continuous, high-volume manufacturing process, little is currently understood about how to best optimize the various process parameters involved. Herein, we investigate the use of a batch mixer that has been previously used in polymer processing, to optimize mechanochemical reactions performed by extrusion. In particular, reactions between 8-hydroxyquinoline $(\mathrm{Hq})$ and metal acetate salts of zinc or aluminum to give quinolinate complexes $\mathrm{Znq}_{2} \cdot \mathrm{AcOH}$ and $\mathrm{Alq}_{3} \cdot \mathrm{AcOH}$, which are of interest for organic light-emitting diode (OLED) applications, have been investigated. The manner in which the progress of the reaction correlates with the machine torque, temperature, and specific mechanical energy (SME) imparted by the batch mixer has been elucidated. Significantly, this knowledge enabled optimization of the mechanochemical reactions by TSE through the key parameters of screw speed, feed rate, temperature, and particle size.

KEYWORDS: Mechanochemistry, Scale up, Rheogram, Particle size, Rotor speed, Fill volume

\section{INTRODUCTION}

Reactions in solution have now been extensively documented and their mechanisms elucidated. In recent years, there has been increasing interest in reactions that can be carried out by mechanochemical means, usually by grinding two or more solid reactants in the absence (or near absence) of solvent in milling apparatus such as ball mills. ${ }^{1-3}$ Because of its avoidance of solvent, mechanochemistry can potentially provide more sustainable routes to fine chemicals and materials. Mechanochemistry has also been found to lead to the formation of new products, not previously obtained by solvent-based synthesis. ${ }^{4}$ A major drawback of this method has been the limited scalability of the processes, particularly as they tend to be carried out at modest scales in ball mills, typically holding a few grams or exceptionally up to a few hundred grams. ${ }^{5}$ Although much larger industrial ball mills are used widely, they are normally employed for materials processing rather than chemical synthesis. ${ }^{6}$ Another limitation of these mills is that temperature control, while possible, is not standard. ${ }^{5}$

Recent work has been published by Paradkar regarding the larger-scale, continuous synthesis of cocrystals ${ }^{7,8}$ and the cocrystal AMG-512 reported by Amgen, ${ }^{9}$ both employing solvent-free extrusion, and alternatively room-temperature extrusion in the presence of small quantities of solvent (liquid-assisted grinding), such as $\mathrm{CHCl}_{3}{ }^{9,10}$ Furthermore, we have recently employed twin-screw extrusion (TSE; Figure 1)

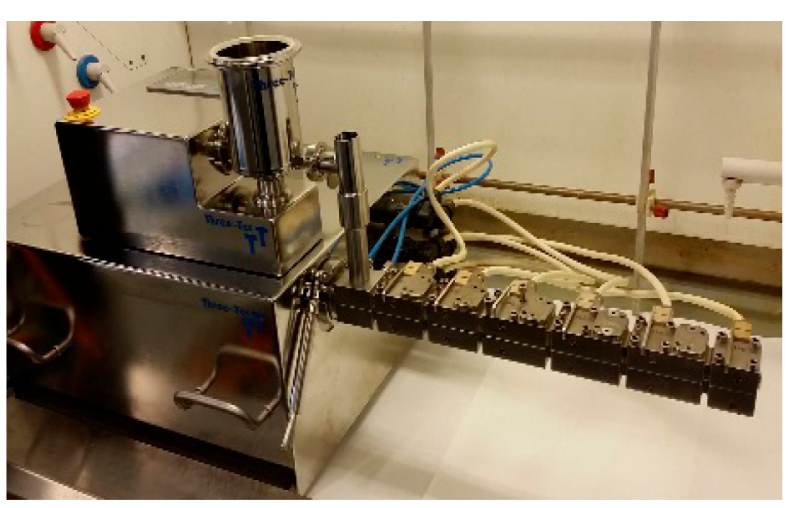

Figure 1. Twin-screw extruder, $12 \mathrm{~mm}, 40: 1 \mathrm{~L} / \mathrm{D}$, consisting of six heating zones with an attached volumetric feeder. ${ }^{13}$

\footnotetext{
Received: July 4, 2017

Revised: $\quad$ September 21, 2017

Published: October 23, 2017
} 
for the continuous mechanochemical synthesis of metal organic frameworks (MOFs), ${ }^{11}$ deep eutectic solvents (DESs), ${ }^{12}$ metal complexes, ${ }^{11}$ and organic compounds. ${ }^{13}$ In the formation of MOFs, highly crystalline products were obtained with $\mathrm{N}_{2}$ Brunauer-Emmett-Teller (BET) surface areas similar to or even greater than those of materials prepared by conventional solvothermal methods. ${ }^{11}$ Furthermore, in the preparation of Dfructose:choline chloride based DES, use of TSE for its synthesis avoided thermal degradation which is a common problem in the traditional batch preparation involving bulk heating. ${ }^{12}$

However, to date there has been little systematic study on the correlation between chemical and extrusion parameters for a given mechanochemical synthesis by TSE, and so optimization has been carried out largely by trial and error. TSE has been widely applied in polymer processing, pharmaceutical formulation, and food production for over 100 years, and there is extensive knowledge of this technique in those contexts. ${ }^{14}$ The knowledge and understanding gained in those applications provides a foundation for understanding the application of TSE to chemical synthesis and thereby provides a more rational basis for process optimization.

In polymer processing, processes are commonly initially investigated and optimized using a small batch mixer, such as the mixer in Figure 2, prior to TSE. This batch mixer allows
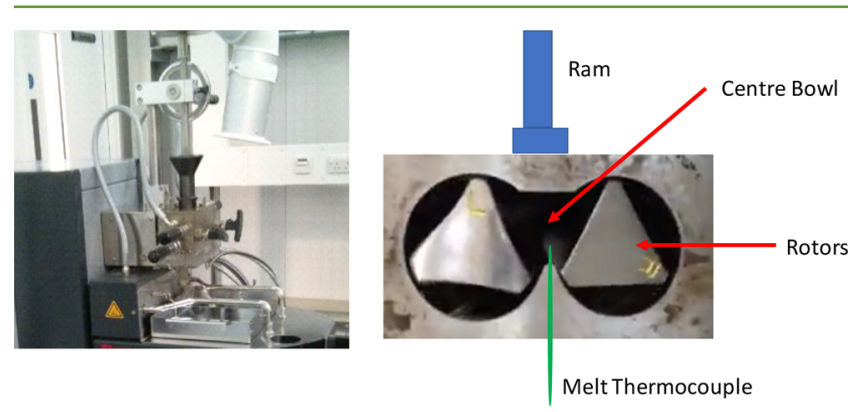

Figure 2. Polylab QC batch mixer and a descriptive diagram of the instrument setup. Modified from ref 17.

investigation of, for example, the viscosity of polymer blends during mixing to provide knowledge which can be applied in larger-scale extrusion. ${ }^{15,16}$

The Polylab batch mixer is designed to mimic a short segment of a twin-screw extruder. Although the rotors are counter-rotating and non-intermeshing, whereas the screws in the extruder experiments described here are corotating and intermeshing, valuable information can still be obtained. The batch mixer consists of three parts: the back panel, the center bowl, and front panel normally made of metal (a transparent Perspex front panel was used in the current work so the reaction could be recorded). The center bowl contains two roller rotors (Figure 3; providing high shear), a thermocouple to record the temperature, and a ram used for charging and sealing the apparatus. The latter was applied with an additional $3 \mathrm{~kg}$ weight to standardize the free volume present in the mixer as well as to help seal the system. Between the rotors there is free volume, containing the thermocouple, through which the material being mixed can pass from one rotor to the other, a process which mimics the conveyance of material from one screw to the other in a twin-screw extruder.

The rotor speed is maintained at a constant rate for each experiment. As material is loaded and mixing begins the rotors

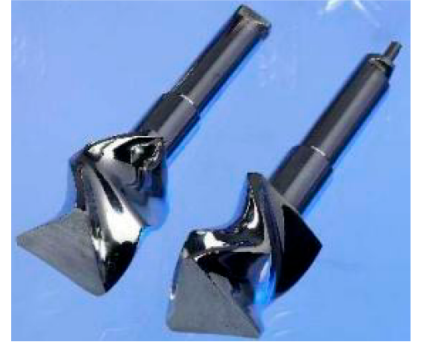

Figure 3. Roller rotors employed in the batch mixer.

experience fluctuations in torque as the rheological properties of the material change. Torque $(\mathrm{N} \mathrm{m})$, temperature $\left({ }^{\circ} \mathrm{C}\right)$, and total energy input $(\mathrm{J})$ are typically plotted against time to provide a rheogram. Figure 4 shows an example of a rheogram

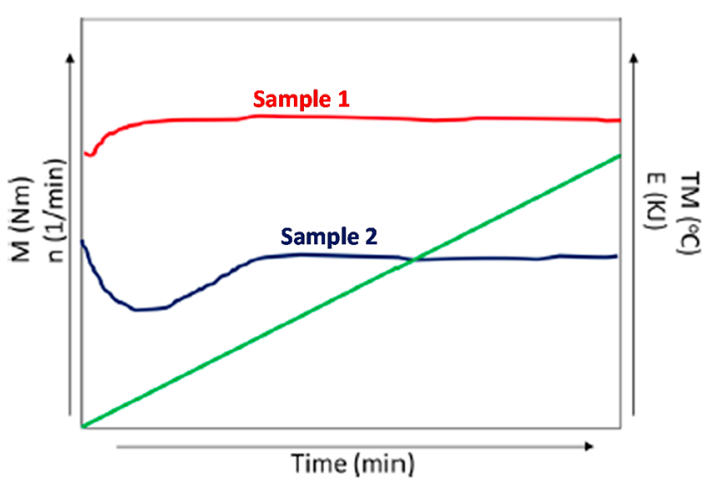

Figure 4. Rheogram of PVC in the presence of DOP plasticizer. Modified from ref 18 .

obtained when polyvinyl chloride (PVC) resin is mixed in a batch mixer with varying amounts of dioctyl phthalate (DOP) plasticizer. ${ }^{18}$ The rheogram illustrates the effect of increasing the amount of DOP on machine torque, blend temperature, and total energy input. At time $=0 \mathrm{~min}$, for both sample 1 (43 phr DOP) and sample 2 (75 phr DOP), there is a sharp increase in torque, which results from introducing the material to the mixer and sealing with the ram. This is known as the loading point. After this the torque rapidly decreases to a minimum. For sample 1, this initial minimum of $5 \mathrm{~N}$ m occurs ca. $0.5 \mathrm{~min}$ before that for sample 2. Furthermore, within the initial $1.6 \mathrm{~min}$, there is a temperature increase of both samples as a result of frictional and material heating. For sample 1, the torque then begins to increase again, and PVC fusion is considered to take place. Sample 2, however, does not experience any increase in torque until after ca. $1.6 \mathrm{~min}$. Stable torque and temperature curves are observed for both samples, highlighting the interdependence of mechanical shear and process temperature. ${ }^{18}$ From these observations it was determined that the addition of plasticizer resulted in a lower PVC melt viscosity, as indicated by the lower torque value observed for sample 2, at ca. $5 \mathrm{~N} \mathrm{~m}$, whereas sample 1 had a larger torque value of ca. $9 \mathrm{~N} \mathrm{~m}$. As viscosity increases, so does the resistance felt by the rotors, leading to an increased machine torque being measured.

The aim of the current work was to investigate how the use of a batch mixer could provide insight into a mechanochemical reaction and thereby provide a rational basis for optimizing the mechanochemical reaction in a twin screw extruder. Specifically, we investigated the reaction between 8-hydroxyquinoline 
Scheme 1. Reaction of 8-Hydroxyquinoline with Basic Aluminum Acetate and Zinc Acetate Dihydrate

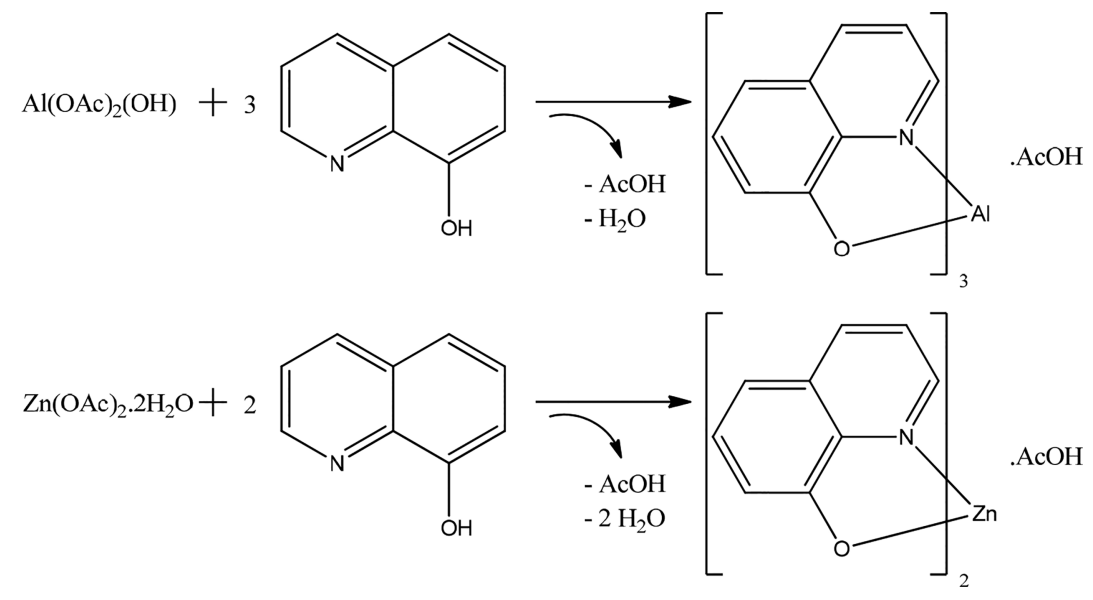

$(\mathrm{Hq})$ and zinc acetate dihydrate or basic aluminum acetate salts to give quinolinate complexes $\mathrm{Znq}_{2} \cdot \mathrm{AcOH}$ and $\mathrm{Alq}_{3} \cdot \mathrm{AcOH}$. These products are of interest as components in organic lightemitting diodes (OLEDs) and have been prepared previously by ball milling. ${ }^{19-21}$ In this study we consider how particle size, rotor speed, fill volume, and temperature correlate with the progress of the reaction in the batch mixer and subsequently apply the findings to the optimization of the synthesis of both products by extrusion.

\section{EXPERIMENTAL SECTION}

All materials were purchased from Sigma-Aldrich UK with $>98 \%$ purity and were used as received, or ball milled and then sieved to a particle size of $355 \mu \mathrm{m}$. Batch mixing experiments were carried out using a ThermoScientific Haake Polylab mixer. Extrusion was carried out using a Three-Tec $12 \mathrm{~mm}, 40: 1 \mathrm{~L} / D$ corotating twin screw extruder with six heating zones.

Batch Mixing Experiments. The 8-hydroxyquinoline was mixed manually with either zinc acetate dihydrate or basic aluminum acetate and fed into a ThermoScientific Haake Polylab mixer while the rotors were turning (at either 30, 55, or $75 \mathrm{rpm}$ ). Quantities of reagents were added to fill the mixer to fill volumes of $45 \%, 60 \%$, or $70 \%$. The mixer was then sealed with the ram, and a $3 \mathrm{~kg}$ weight was put on top of the ram. After the first fluctuation of $\leq 0.5 \mathrm{~N} \mathrm{~m}$, any further change in torque was recorded automatically by the software. The experiments were allowed to run for a given time. Samples were taken from the rotors, the sides of the central bowl, and the free volume between the rotors and characterized (by PXRD analysis, using a flat silicon background disc).

Extrusion Experiments. A mixture of 8-hydroxyquinoline (with a particle size of $300 \mu \mathrm{m}$ ) and either zinc acetate dihydrate or basic aluminum acetate were added to a Three-Tec volumetric feeder. The material was then fed into the twin screw extruder, set at a screw speed of $150 \mathrm{rpm}$ (for the $\mathrm{Znq}_{2} \cdot \mathrm{AcOH}$ system) or $55 \mathrm{rpm}$ (for the $\mathrm{Alq}_{3}$. $\mathrm{AcOH}$ system). After several minutes, product was extruded and then oven heated at $100{ }^{\circ} \mathrm{C}$ for $1 \mathrm{~h}$ to remove excess acetic acid.

\section{RESULTS AND DISCUSSION}

Initially, the reaction between zinc acetate dihydrate and 8hydroxyquinoline (Scheme 1) was studied in some detail using the batch mixer, and it was found that changing the rotor speed and fill volume directly affected the overall torque recorded, as well as the time required for the torque to increase. The observed increase in torque was found to indicate the onset of the chemical reaction (as determined by the change in color and by PXRD analysis). The corresponding increase in viscosity implied by the increase in torque may relate to the formation of the liquid byproducts water and acetic acid which serve to bind the powders into pastes. Interestingly, a change in the shape of the torque versus time graph was also observed upon changing the particle size of Hq. The trends established through these experiments were further confirmed by experiments conducted between $\mathrm{Hq}$ and basic aluminum acetate, confirming that the trends are not system specific and may be applied to other reactions under investigation by extrusion.

Particle Size. Hq (Figure 5) is obtained commercially as flakes, ranging in diameter from ca. 5 to $7 \mathrm{~mm}$, and this form of

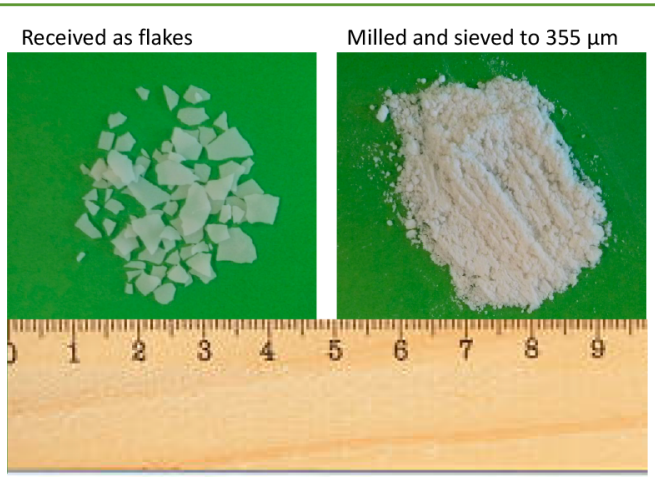

Figure 5. Photographs of 8-hydroxyquinoline in both its flake (left) and powder (right) form.

the material was employed along with a powdered form (obtained by milling and sieving) with a particle size of $355 \mu \mathrm{m}$. In all experiments the particle size of the metal salt was kept constant at $300 \mu \mathrm{m}$. For investigating these solid-solid reactions, it was found that a minimum fill volume of $60.0 \%$ was required for any fluctuations in torque to be observed. The rotor speed in this study was set at $55 \mathrm{rpm}$, in common with the screw speed in the extrusion process we utilized previously. ${ }^{11-13}$

After the rotors were started the reagents were added, and the mixer was sealed by lowering the ram and applying a $3 \mathrm{~kg}$ weight. When the flake form of $\mathrm{Hq}$ was used there was an audible "crunching" of the material which was not heard when it was used in powder form. For both particle sizes studied there was a rapid change of color observed (within $30 \mathrm{~s}$ ), from the white of the reactants to the expected vibrant yellow of the product. In addition, there was an associated visible change in 

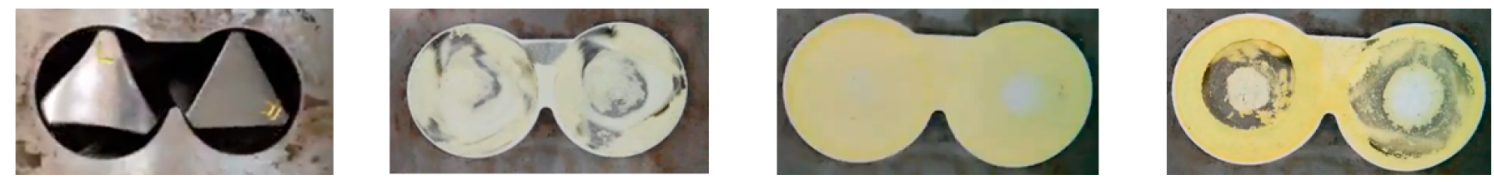

Figure 6. Photographs depicting the changes in the reaction between 8-hydroxyquinoline and zinc acetate dihydrate in the batch mixer, viewed through a Perspex cover, over a period of $1.5 \mathrm{~min}$.

the rheology of the material in the mixer from free-flowing powder to a more viscous paste as depicted in Figure 6.

These visible changes coincided with an increase in the measured torque. For the experiment with flake $\mathrm{Hq}$, a maximum torque of ca. $16 \mathrm{~N} \mathrm{~m}$ was reached after $1.5 \mathrm{~min}$ (Figure 7 ). With the powder form, the maximum torque was

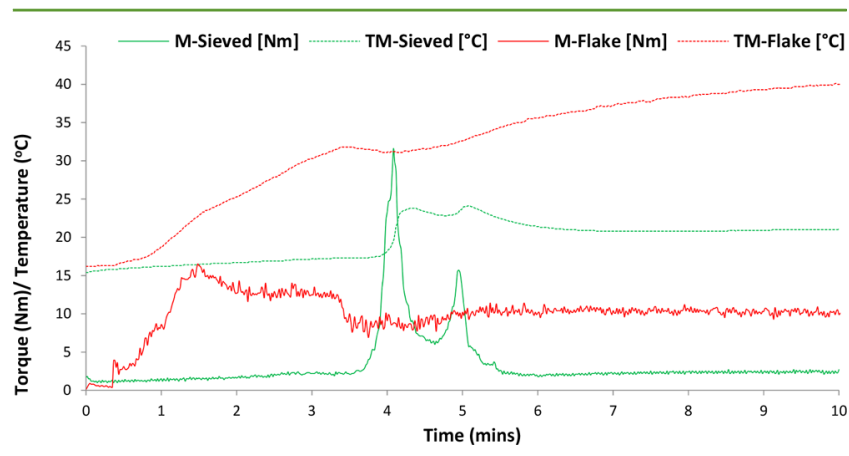

Figure 7. Rheogram of reaction between 8-hydroxyquinoline with large particle size (red) and small particle size (green) and zinc acetate dihydrate ( $\mathrm{M}$ indicates torque, TM indicates temperature).

reached somewhat later, at $4.1 \mathrm{~min}$, but the maximum value observed was significantly greater at ca. $31 \mathrm{~N} \mathrm{~m}$. The flakes resulted in a relatively broad peak in torque that slowly gave way to a steady value of ca. $10 \mathrm{~N} \mathrm{~m}$ after ca. $4 \mathrm{~min}$. The powder form gave a sharper, better-defined peak, clearly consisting of two individual maxima. Specifically, after peaking at $31 \mathrm{~N} \mathrm{~m}$, the torque dipped to $6 \mathrm{~N} \mathrm{~m}$, then increased to $14 \mathrm{~N} \mathrm{~m}$, before decreasing and remaining at a relatively low value of ca. $2 \mathrm{~N} \mathrm{~m}$ (Figure 8).

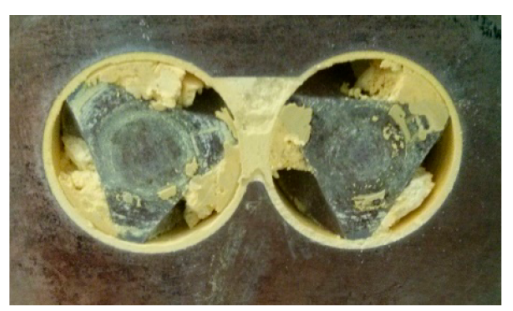

Figure 8. Photograph taken after the experiment was stopped. Material seen to coat the sides of the center bowl and the grooves of the rotors.

Furthermore, temperature rises occurred which closely followed the timing and form of the torque versus time traces for each experiment. For the flakes, the temperature began to rise slightly after the rise in torque, increasing by ca. $15^{\circ} \mathrm{C}$ after $3.5 \mathrm{~min}$. As the torque then decreased the temperature also decreased briefly by $2{ }^{\circ} \mathrm{C}$ before rising again steadily during the course of the experiment to a final value of ca. $40^{\circ} \mathrm{C}$. With the powder form of $\mathrm{Hq}$, the increase in temperature occurred later (again coinciding with the increase in torque) and was less pronounced $\left(6^{\circ} \mathrm{C}\right)$. The temperature finally settled at ca. $20^{\circ} \mathrm{C}$ and remained there for the duration of the experiment (only 4 ${ }^{\circ} \mathrm{C}$ above the starting temperature). Presumably, this behavior is associated with the ability of the greater surface area of the powder to dissipate heat compared to the flake. ${ }^{22}$

From close visual observation of the experiments, the subsequent decrease in torque coincided with the material no longer being effectively mixed. In particular, the material was seen to collect as a coating on the sides of the center bowl, which remained there as a result of the sticky consistency of the material, as seen in Figure 8. Because of the clearance between the rotors and the sides of the center bowl there was no longer any mixing of the material in this region. Also, material was seen to collect in the grooves of the rotors, moving smoothly with the rotors. Finally, material also collected in the central region between the two rotors.

Upon opening the mixer after the experiment, the material was found to be hard and difficult to break up and remove. The material which had collected in the central region had essentially blocked that area, and would have prevented any movement and transfer of material from one rotor to the other. However, since the visible changes in color and particularly rheology had occurred before this region became blocked, we consider that this blocking does not hinder interpretation of the key results.

PXRD analysis was used to correlate the progress of the reaction with the observed changes in torque and temperature (Figure 9). After mixing for 20 and $90 \mathrm{~min}$, although the

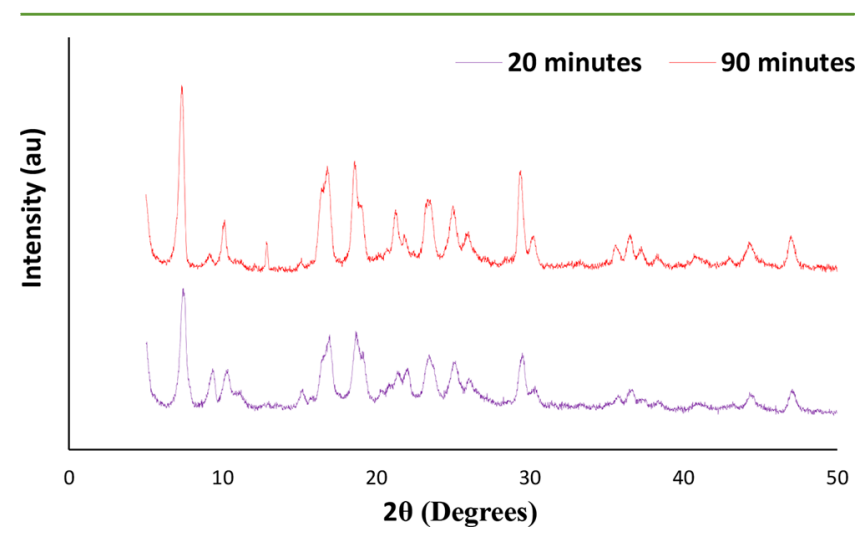

Figure 9. PXRD patterns of the mixture obtained from the batch mixer at 20 and $90 \mathrm{~min}$.

expected product was observed in the PXRD patterns, and a color change had occurred, the reaction mixture was found by PXRD to consist primarily of the starting materials. The experiments were then repeated, but sampled just before the initial increase in torque. Although a slight change in the color of the material had occurred (to a very pale yellow) at this stage, PXRD analysis showed the presence of only starting materials, and they could be seen to separate easily from one another. This indicates that the reaction is initiated principally during the rise in torque. A further experiment was sampled 
when the torque was greatest, and PXRD analysis indicated the presence of product, supporting this hypothesis further. We note that even mixing for $90 \mathrm{~min}$ did not result in a complete reaction, suggesting that after the material coats the sides of the center bowl, mixing is inefficient, and so the reaction stops. Although a complete reaction was not obtained in the batch mixing process, significant information can still be obtained about the initiation of the reaction and its relation to the extrusion process.

A clear relationship between the rheological and chemical aspects of the reaction has been revealed by these experiments, since the initiation of the reaction coincides with changes in rheological properties. From the visible and recorded observations, several deductions can now be made regarding the processing of the reaction between $\mathrm{Hq}$ and metal acetate salts in the solid state.

First, the experiment where the $\mathrm{Hq}$ consisted of large flakes initiated more quickly $(0.5 \mathrm{~min})$ than when it consisted of a powder $(3.5 \mathrm{~min})$. This result is very surprising as it is typically expected that reagents of smaller or similar particle size should react more quickly due to the greater potential for surface contact between the reactants. ${ }^{23}$ We suggest three possible explanations as to why the opposite occurs in the current system. (1) The large brittle flakes may act themselves as additional grinding media, thereby promoting mixing and causing the reaction to initiate more quickly. (2) As the flakes are very large and brittle, they are more readily broken than the small particles, potentially leading to a higher number of fresh reactive surfaces being formed during the initial stages of the experiment. (3) Upon milling of the Hq flakes, the surface may passivate and be rendered less reactive or unreactive, perhaps as a result of the more intimate contact with atmospheric moisture.

At this point it is pertinent to consider the observed torquetime graphs in more detail. When $\mathrm{Hq}$ is used in flake form, the peak observed is broad and ill-defined compared to when it is used in powder form. Whereas the powder form gives rise to two well-defined peaks, the second being less intense than the first, for the flake form these features appear to have broadened and merged together. Therefore, despite their differences there is clearly a resemblance between the shapes of the peaks observed for the flakes and for the powder. A better-defined peak for the powder most likely reflects the similar particle sizes of the two reactants, and the fact that these particle sizes may not change greatly over time. By contrast, the less homogeneous mixture present when large flakes of $\mathrm{Hq}$ are used, together with changes in particle size over time as the flakes are crushed, can be expected to give rise to a broader torque-time response.

The mechanical energy put into the system is represented by the areas under the peaks and by the energy consumption reported on the rheogram. ${ }^{24}$ It is interesting to note that the energy input is greater for the flakes than for the powder, indicating that more work is being done to break down the flakes and potentially to mix the reactants, which is consistent with the earlier initiation of the reaction. The greater increase in temperature observed for the flakes may also reflect the greater mechanical energy input, although contributions due to a possible reaction exotherm cannot be ruled out. Careful visual observation of the mixing process also revealed the origin of the double-peak shape in the torque-time graphs. It was observed that the drop in torque after the first maximum occurred simultaneously to material transferring from one rotor zone to the other. As the material collected briefly in the middle of the center bowl, the torque decreased, and as it transferred to and was mixed by the second rotor, there was a second increase in torque. The maximum torque at this second stage can be expected to be less than the first, since some mixing and working of the material had already taken place. The process involved mainly pushing the material to the sides of the center bowl and into the grooves of the rotors as the torque finally plateaued at a lower value (please see video supplied as Supporting Information).

The experiments described above were each repeated three times to ensure reproducibility. Furthermore, a second, related system was investigated, specifically the reaction between basic aluminum acetate and 3 equiv of $\mathrm{Hq}$. The process parameters were kept constant, i.e., rotor speed of $55 \mathrm{rpm}$, fill volume of $82.5 \%$, and particle size of the metal salt of $300 \mu \mathrm{m}$. In this system, $\mathrm{Hq}$ was again studied in both its flake form and after milling and sieving to $355 \mu \mathrm{m}$.

The rheograms obtained in these experiments indicated that the same general trends were present as in the $\mathrm{Zn}$ system (Figure 10). In addition, the visible changes to the nature of the

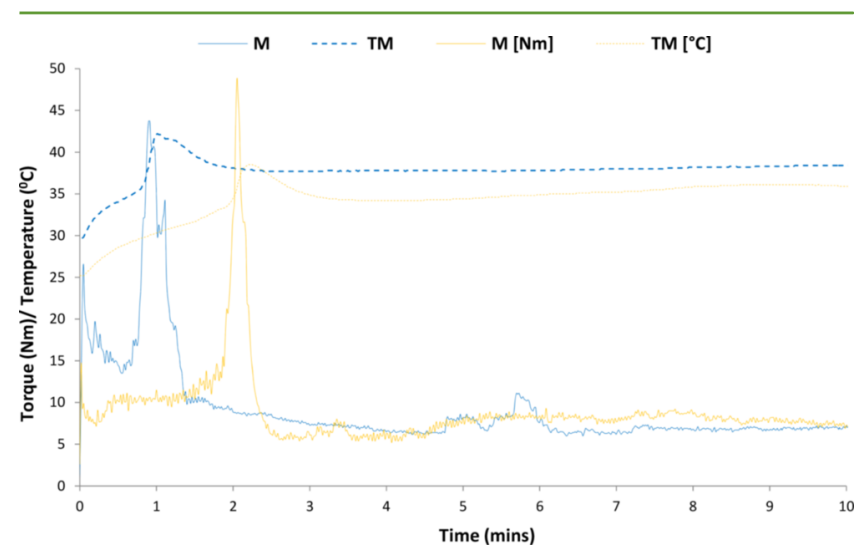

Figure 10. Rheogram of reaction between 8-hydroxyquinoline with large particle size (blue) and small particle size (orange) and basic aluminum acetate ( $\mathrm{M}$ indicates torque, TM indicates temperature).

material and with regards to PXRD analysis were analogous to those in the $\mathrm{Zn}$ system (significant amount of starting material residing, Figure 11). However, in this case the effect of the filling of reagents, i.e., the loading point, when the torque dramatically increases as a result of the addition of the material and sealing with the ram, was also observable in the rheograms. This loading also led to an increase in the temperature so that

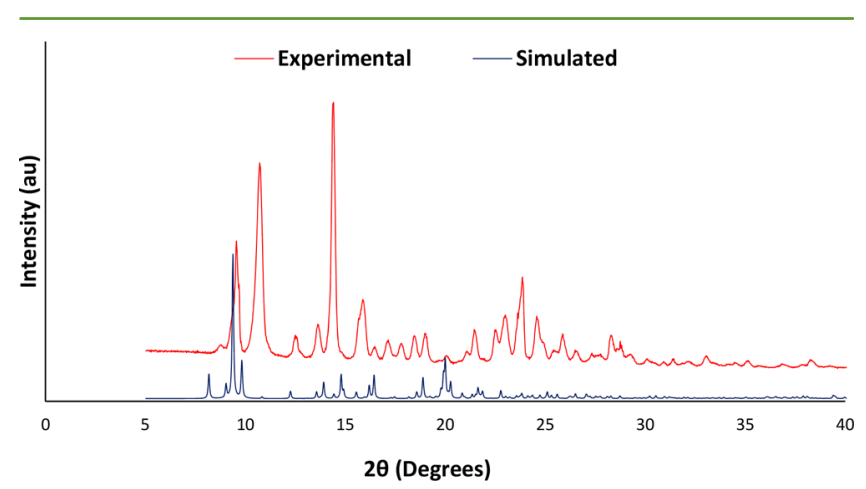

Figure 11. PXRD patterns of the mixture obtained from the batch mixing of basic aluminum acetate and 3 equiv of $\mathrm{Hq} .{ }^{21}$ 
the temperature at the start of these experiments was $25-30{ }^{\circ} \mathrm{C}$ compared to $15{ }^{\circ} \mathrm{C}$ in the $\mathrm{Zn}$ system, and in which the loading of material did not appear to result in an increase in torque at time $=0 \mathrm{~min}$.

Once again, employing $\mathrm{Hq}$ in its flake form resulted in the initiation of the reaction earlier than when the powder form was used. Also, an associated rise in temperature was observed as before, with the reaction between the larger particles of $\mathrm{Hq}$ and metal salt resulting in a greater increase of ca. $7{ }^{\circ} \mathrm{C}$ compared to $4{ }^{\circ} \mathrm{C}$ for the powder form.

It can be seen that the shapes of the torque versus time graphs are similar to each other but different to those observed in the $\mathrm{Zn}$ system. Additionally, in contrast to the $\mathrm{Zn}$ system, there is relatively little difference in the maximum torque observed for the flake $(43 \mathrm{~N} \mathrm{~m})$ and powder $(48 \mathrm{~N} \mathrm{~m})$ forms. There also does not appear to be a large difference in mechanical energy input for the two cases. However, the flakes give rise to a torque peak that is marginally broader and so may be considered to follow the same trend as seen previously.

An explanation as to why the areas under the curves are not dramatically different and why the graphs do not show the same double-peak shape seen in the $\mathrm{Zn}$ system may lie in the higher starting temperature. In the experiments involving $\mathrm{Zn}$, the loading point was not observed, and so there was no immediate increase in temperature as occurs with the $\mathrm{Al}$ system. This temperature difference could cause a difference in the rheology of the material and the time taken for each reaction to initiate. ${ }^{25}$ The material may be less viscous at higher temperatures and so may pass more rapidly from one rotor to another so that double peaks are not observed.

Overall, compiling the results from both systems, similar behavior has been observed between $\mathrm{Zn}$ and $\mathrm{Al}$ systems suggesting that process optimization under TSE should be similar for both systems. It was found that, counterintuitively, larger particles (flakes) lead to faster initiation of the reaction in this shear-based system. This is ascribed to the flakes acting as grinding media and/or to formation of fresh reactive surfaces when mixing with $\mathrm{Hq}$ flakes. However, it was also noted that larger particles required more energy input than when using smaller particles.

Rotor Speed. Again, the reaction between zinc acetate dihydrate and $\mathrm{Hq}$ was investigated initially, and as a welldefined torque versus time graph was obtained when using $\mathrm{Hq}$ powder of $355 \mu \mathrm{m}$ particle size, this powder form was also employed in the following experiments. Although screw speeds in TSE can reach up to hundreds of rpm, the rotor speeds investigated in the batch mixer were chosen as 30,55 , and 75 $\mathrm{rpm}$, as these have been demonstrated as typical screw speeds in chemical synthesis by extrusion. A fill volume of $60.0 \%$ was employed, and the same trends in changes in rheology, rise in torque, and temperature were observed as previously (Figure 12). Furthermore, at each rotor speed, the same torque versus time peak shape (double peaks with the first peak more intense than the second) was observed, attesting further to the generality of this behavior.

Upon increasing rotor speed from 30 to $55 \mathrm{rpm}$, there does not appear to be a significant difference in the time required to initiate the reaction as judged by the increase in torque. There is also little difference in the maximum torque value observed at each rotor speed, as mixing at $55 \mathrm{rpm}$ results in a maximum torque of $31.6 \mathrm{~N} \mathrm{~m}$, only $5 \mathrm{~N} \mathrm{~m}$ less than mixing at $30 \mathrm{rpm}$. However, the mechanical energy input is significantly greater at $30 \mathrm{rpm}$ than at $55 \mathrm{rpm}$. This is the most significant difference

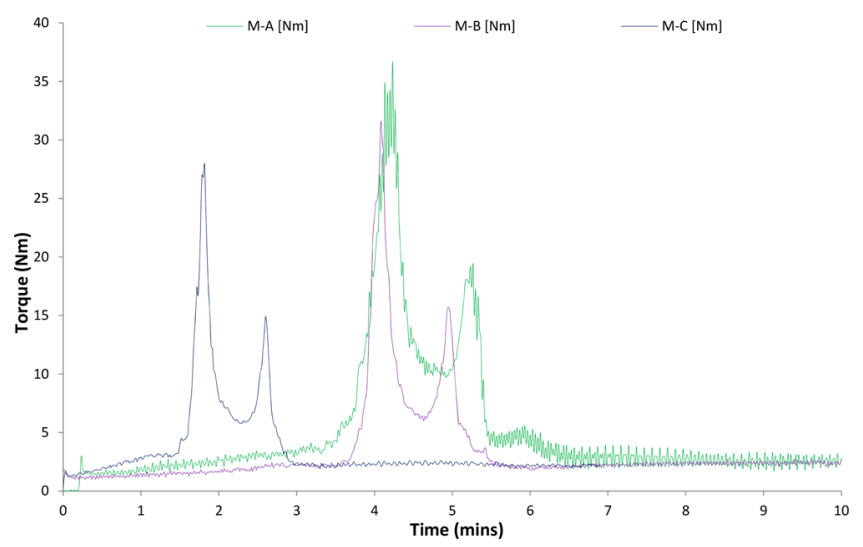

Figure 12. Rheogram of reaction between zinc acetate dihydrate and 8-hydroxyquinoline $(355 \mu \mathrm{m})$ at 30 (green), 55 (purple), and 75 (navy) rpm ( $\mathrm{M}$ indicates torque, TM indicates temperature).

observed between both of these speeds. A more dramatic difference is observed when increasing the rotor speed from 55 to $75 \mathrm{rpm}$. Here, although the difference in torque is again relatively small (ca. $3 \mathrm{~N} \mathrm{~m}$ ), the time taken for the reaction to initiate is halved from 4 to $2 \mathrm{~min}$ by increasing the rotor speed.

In analogous experiments involving basic aluminum acetate and $\mathrm{Hq}$ powder $(355 \mu \mathrm{m})$, the same trend is observed in that increasing rotor speed can substantially decrease the reaction initiation time. As can be seen in Figure 13, increasing rotor

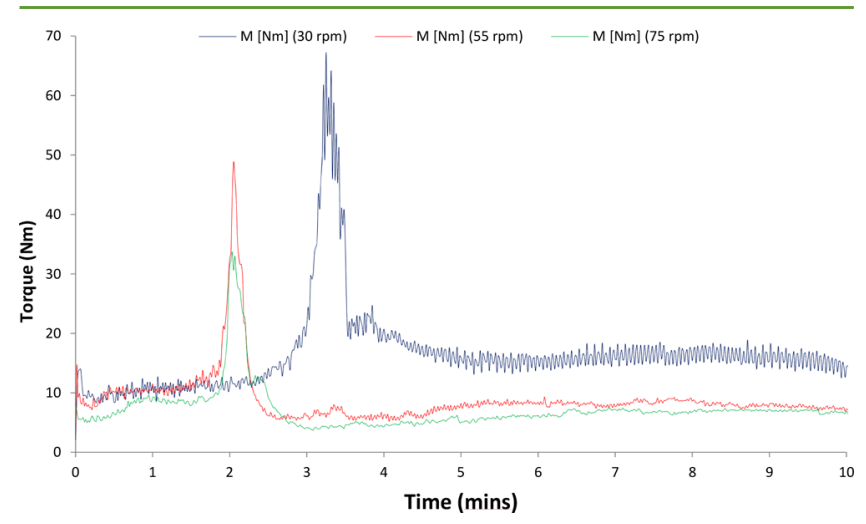

Figure 13. Rheogram of reaction between basic aluminum acetate and 8-hydroxyquinoline $(355 \mu \mathrm{m})$ at 30 (navy), 55 (red) and 75 (green) rpm ( $\mathrm{M}$ indicates torque, TM indicates temperature).

speed in this case from 30 to $55 \mathrm{rpm}$ reduces the initiation time from 3.5 to $2 \mathrm{~min}$. Furthermore, there is a decrease in maximum torque of ca. $20 \mathrm{~N} \mathrm{~m}$; this is because the rotors are moving faster, and so there is a higher energy input from the mixer, which results then in the ability to move the material more easily. Upon increasing the rotor speed from 55 to 75 $\mathrm{rpm}$, there is no decrease in the time required to instigate a reaction, but there is a clear decrease in the torque recorded, of ca. $16 \mathrm{~N} \mathrm{~m}$.

From this set of results, it can be seen that increasing the rotor speed can dramatically decrease the time required for the reaction to be initiated, and furthermore in some cases the torque and required mechanical energy also decrease. However, it is interesting that this only occurs over particular ranges of rotor speed, since in some cases increasing the rotor speed does not reduce the initiation time. As in some cases, there appears to be a limit as to how short the reaction initiation is, for 
example, in the $\mathrm{Al}$ system, a minimum of ca. 2 min is recorded, this may indicate that there is a minimum residence time (time required to obtain efficient mixing in a batch or continuous vessel), for a given rotor or screw profile, required before the reaction can begin. Therefore, a fine balance may exist between the screw (or rotor) speed and the residence time for a process to be optimized.

Fill Volume. The fill volume in the batch mixer relates to the rate at which material is fed into a twin-screw extruder, and has a direct effect on the compressive forces present in a system. For the $\mathrm{Zn}$ system we investigated fill volumes of $45.2 \%, 50.0 \%, 60.0 \%$, and $82.5 \%$. The flake form of $\mathrm{Hq}$ was used as this was more sensitive to small fluctuations in torque (with the powder form, changes in torque were quite minor and difficult to detect when lower fill volumes were employed).

As expected, increasing the fill volume resulted in an increase in torque, but, more interestingly, had a greater effect on the mechanical energy input (Figure 14). As the fill volume

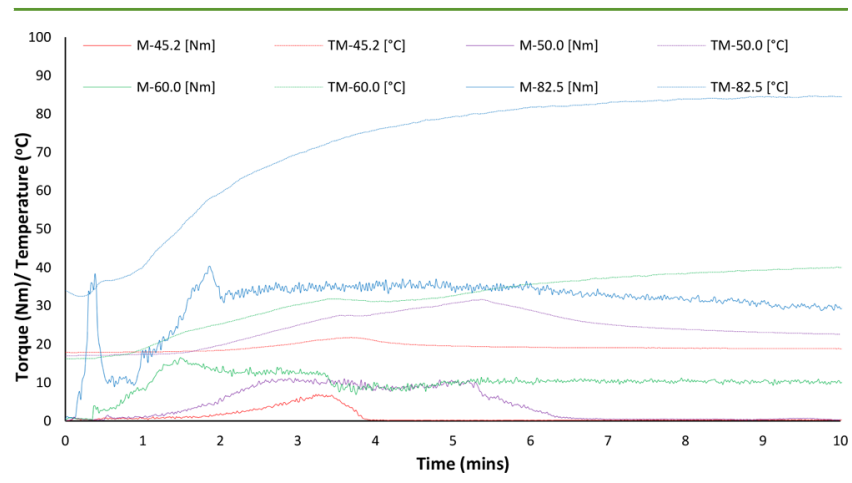

Figure 14. Rheogram of reaction between zinc acetate dihydrate and 8-hydroxyquinoline at fill volumes of $45.2 \%$ (red), 50.0\% (purple), $60.0 \%$ (green), and $82.5 \%$ (blue) ( $\mathrm{M}$ indicates torque, TM indicates temperature).

increases, the area under the curve also increases, and in the experiments with $82.5 \%$ and $60.0 \%$ fill volumes, the curve plateaus at high torque (ca. $10 \mathrm{~N} \mathrm{~m}$ ). Furthermore, at a fill volume of $50.0 \%$, a shoulder is present on the torque versus time graph. This shows similarity to the experiments carried out with the powder form of $\mathrm{Hq}$ described above, where two torque maxima were clearly observed.

Additionally, there is also a clear difference in the reaction initiation time (i.e. taken as the time at which torque increases). At higher fill volumes the reactions are initiated much earlier, even in less than $30 \mathrm{~s}$, whereas at $45.2 \% 3 \mathrm{~min}$ was required. The temperature increase due to frictional heating was also greater when larger fill volumes were employed, particularly at $82.5 \%$ fill, when almost $90{ }^{\circ} \mathrm{C}$ was reached. The increase in torque and the time required to initiate the reaction are dependent on the total shear and compressive forces present in the batch mixer, and this is dramatically increased with increased fill volume. ${ }^{26}$ At high fill volumes, the amount of mechanical energy applied to the system is also greater, as indicated by the larger area under the curve, and particularly as the torque remains at $\mathrm{ca} .40 \mathrm{~N} \mathrm{~m}$, throughout the rest of the experiment, ca. $30 \mathrm{~N} \mathrm{~m}$ higher than when a lower fill volume of $60.0 \%$ was employed.

Experiments carried out with basic aluminum acetate showed a similar trend: i.e. as the fill volume was increased, the initiation time was reduced. However, in this case at fill volumes of less than $82.5 \%$, fluctuations in torque were insignificant and could not be used to assess reaction initiation. Therefore, the fill volume was increased to $94 \%$. At $94.0 \%$, the torque increased more rapidly than at $82.5 \%$, taking $1 \mathrm{~min}$ to reach a maximum of $46 \mathrm{~N} \mathrm{~m}$, whereas at $82.5 \%$, it took $2 \mathrm{~min}$ to reach a similar torque maximum of $48 \mathrm{~N} \mathrm{~m}$ (Figure 15).

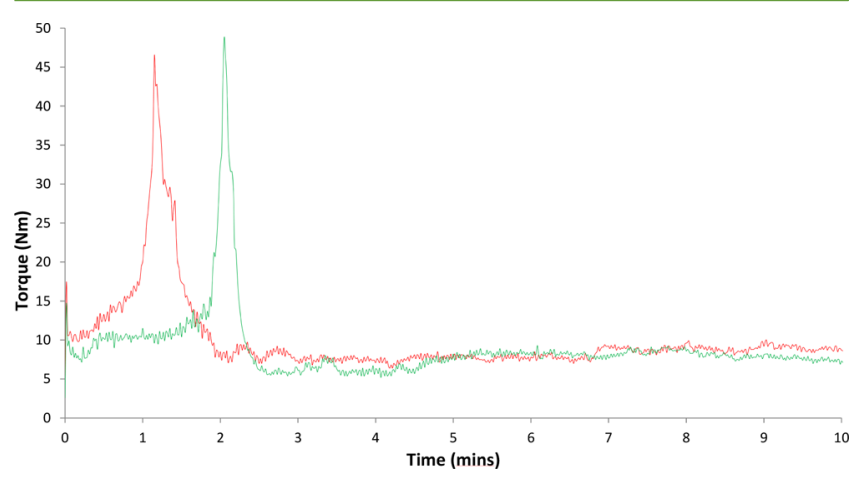

Figure 15. Rheogram of reaction between basic aluminum acetate and 8-hydroxyquinoline at fill volumes of $94.0 \%$ (red) and $82.5 \%$ (green).

Although there is very little difference in these torque maxima, there is clearly a difference in the area under the curves with greater mechanical energy input occurring at the higher fill level.

Temperature. Unfortunately, because of the leaking of molten $\mathrm{Hq}$ out of the batch mixer, experiments could not be carried out at or above the melting point of $\mathrm{Hq}\left(76{ }^{\circ} \mathrm{C}\right)$, preventing a full study into the effect of temperature, a critical process parameter. However, in the $\mathrm{Zn}$ system with powdered $\mathrm{Hq}$, some conclusions can be drawn by comparing experiments conducted at 15 and $22{ }^{\circ} \mathrm{C}$. Although a seemingly small temperature difference (i.e., $7{ }^{\circ} \mathrm{C}$ ), this actually led to a significant difference in the reactivity of the materials. Figure 16

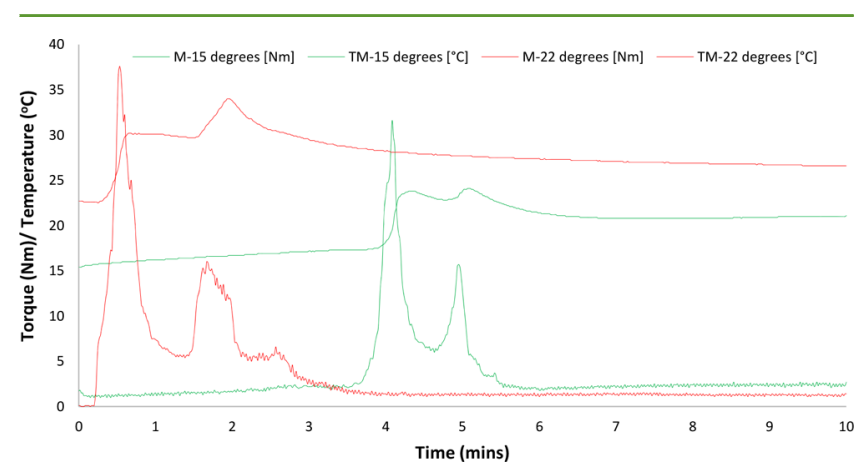

Figure 16. Rheogram of reaction between zinc acetate dihydrate and 8-hydroxyquinoline at temperatures of 15 (green) and 22 (red) ${ }^{\circ} \mathrm{C}(\mathrm{M}$ indicates torque, TM indicates temperature).

shows the rheograms for each experiment, and it can clearly be seen that the shapes of the torque versus time graphs are similar. However, at $22{ }^{\circ} \mathrm{C}$ the torque maximum is reached within ca. $30 \mathrm{~s}$ of mixing, whereas, at $15{ }^{\circ} \mathrm{C}$, almost $4 \mathrm{~min}$ passes before any increase in torque can be observed. All other parameters were kept constant (60.0\% fill volume, $55 \mathrm{rpm})$ except for temperature, and this result highlights how sensitive the reaction is to heating, suggesting also that once temperatures are increased as a result of frictional heating alone, the reaction is likely to proceed more readily as a result of additional heat energy. 
Extrusion. Several trends were established after conducting the above experiments in the batch mixer regarding particle size, rotor speed, fill volume, and temperature. Together, these suggested that TSE carried out at high screw speed, employing the larger $\mathrm{Hq}$ particles (either to act as subsidiary grinding media or to produce more fresh reactive surfaces), with a high fill volume (achieved through a high feed rate) and at a higher temperature would be most efficient for the reaction between $\mathrm{Hq}$ and a metal acetate salt. It was also noted that such conditions generally resulted in high torque values. In achieving these conditions in a twin screw extruder, however, it needs to be borne in mind that twin screw extruders will generally have an automatic safety cut off at high torque values in order to avoid potential damage to the screws.

In studying the synthesis of $\mathrm{Znq}_{2} \cdot \mathrm{AcOH}$ and $\mathrm{Alq}_{3} \cdot \mathrm{AcOH}$ by TSE it was indeed quickly apparent that in order to achieve a complete reaction high torque had to be achieved and maintained, otherwise starting materials would be retrieved from the extruder. This also indicated that a significant amount of mechanical energy was needed to induce a complete reaction.

However, for both reactions, it was found to be most beneficial to employ smaller particles of $\mathrm{Hq}$ (powder form). Extrusion is a continuous flow process, and as such the correct stoichiometry needs to be maintained as the material is conveyed along the length of the extruder barrel. If the stoichiometry is not maintained then the reaction will not proceed to completion. It was found that in premixing the reactants (before feeding into the extruder), $\mathrm{Hq}$ mixed more efficiently with the metal salt when in powder form, leading to a homogeneous mixture being fed into the extruder. Mixtures of Hq flakes and the metal salts tended to separate before feeding, and as a result the stoichiometry of the reaction was difficult to control.

The TSE synthesis of $\mathrm{Znq}_{2} \cdot \mathrm{AcOH}$ was conducted at 20-22 ${ }^{\circ} \mathrm{C}$ since this temperature had been found to be effective in the batch mixer, resulting in a short initiation time of $1 \mathrm{~min}$. Therefore, $1 \mathrm{~min}$ was considered to be the optimum residence time in the extruder for a complete reaction to occur (as determined by PXRD analysis, Figure 17). The process was

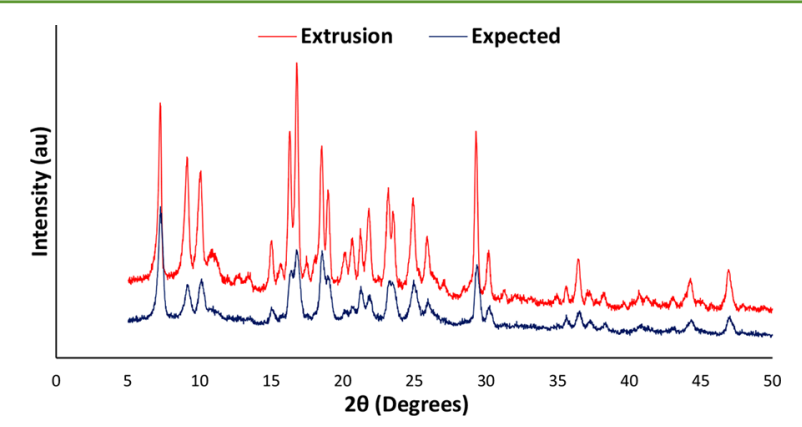

Figure 17. PXRD pattern of $\mathrm{Znq}_{2} \cdot \mathrm{AcOH}$ produced by twin-screw extrusion (red), compared with the expected pattern (blue) for this complex.

therefore optimized so that a reaction would go to completion, within a short residence time of $1 \mathrm{~min}$ and with a screw speed of $100 \mathrm{rpm}$. This resulted in a steady-state torque of $10 \mathrm{~N} \mathrm{~m}$, below the safety cutoff of $15 \mathrm{~N} \mathrm{~m}$. At screw speeds of 30 and 55 $\mathrm{rpm}$, the torque was too high leading to "torqueing out", and at $150 \mathrm{rpm}$ and above, only partial reactions were obtained even with high feed rates, suggesting that the residence time of less than $1 \mathrm{~min}$ was too short. Furthermore, in order to keep the torque consistently at ca. $10 \mathrm{~N} \mathrm{~m}$, a feed rate of $2.5 \mathrm{~g} \mathrm{~min}^{-1}$ was used, which helped maintain the high torque. Again increasing this parameter further caused the machine to "torque out".

For the synthesis of $\mathrm{Alq}_{3} \cdot \mathrm{AcOH}$ by TSE, similar considerations again led to an effective optimized process. However, a range of screw speeds and feed rates at room temperature all lead to high torque values that fluctuated and were difficult to regulate. To overcome this problem, we considered that a higher temperature might be beneficial for the rheology of the material, specifically making it less viscous. When the temperature was increased to $65{ }^{\circ} \mathrm{C}$ the material flowed more easily; the torque fluctuated less and was easier to control. The optimized process used a slower screw speed of $55 \mathrm{rpm}$, which gave a residence time of $2 \mathrm{~min}$. With a greater feed rate of $4 \mathrm{~g}$ $\mathrm{min}^{-1}$, the torque could be maintained relatively high at $9 \mathrm{~N} \mathrm{~m}$, and $\mathrm{Alq}_{3}$ was isolated as a bright yellow fine powder (Figure 18). It must be noted that the PXRD pattern expected in this

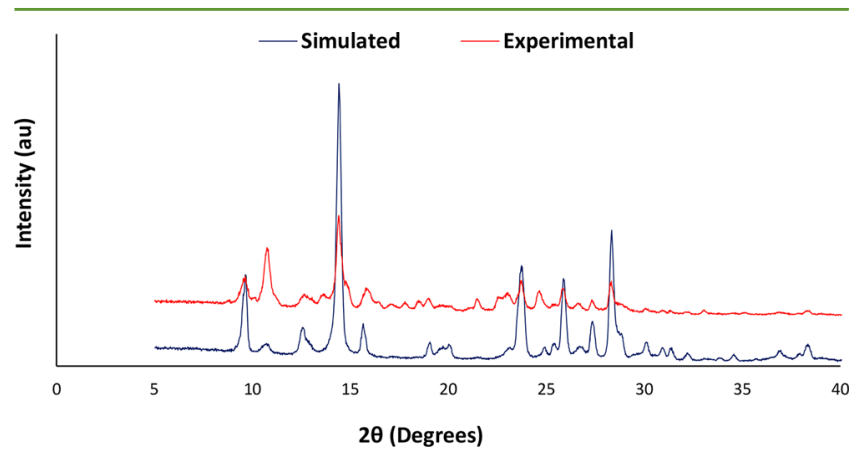

Figure 18. PXRD pattern of $\mathrm{Alq}_{3}$ produced by twin screw extrusion (red), compared with the simulated pattern (blue) for this complex (CCDC: QATMONO1 without AcOH).

case is different, as because of the temperature used in the extrusion process, the product is obtained in the absence of $\mathrm{AcOH}$, which is lost as vapor.

As the synthesis of $\mathrm{Znq}_{2}$. $\mathrm{AcOH}$ was conducted essentially at room temperature, and $\mathrm{Alq}_{3} \cdot \mathrm{AcOH}$ at $65{ }^{\circ} \mathrm{C}$, there were still small amounts of acetic acid and water present at the end of the process. Therefore, before elemental analysis was conducted, samples of materials were dried under mild conditions, by heating at $100{ }^{\circ} \mathrm{C}$, for $1 \mathrm{~h}$. CHNS analysis indicated that the products were prepared in an analytically pure form (see the SI).

\section{CONCLUSION}

We have demonstrated that using a small batch mixer to study the mixing of and mechanochemical reaction between two solids under solvent-free conditions can help to intelligently optimize mechanochemical synthesis by twin screw extrusion, a continuous process that can produce products in high volumes and low cost. Information obtained from batch mixing with regard to rotor speed, fill level, and temperature made optimization of the TSE synthesis more systematic than the current largely trial-and-error process. This enabled the continuous solvent-free synthesis of $\mathrm{Znq}_{2} \cdot \mathrm{AcOH}$ and $\mathrm{Alq}_{3}$. $\mathrm{AcOH}$ which are of interest as OLED materials. 


\section{ASSOCIATED CONTENT}

\section{S Supporting Information}

The Supporting Information is available free of charge on the ACS Publications website at DOI: 10.1021/acssuschemeng.7b02202.

Video of the batch mixer in process (AVI)

\section{AUTHOR INFORMATION}

\section{Corresponding Authors}

*E-mail: d.crawford@qub.ac.uk.

*E-mail: t.mcnally@warwick.ac.uk.

ORCID $\odot$

Deborah E. Crawford: 0000-0003-2579-7987

Notes

The authors declare no competing financial interest.

\section{ACKNOWLEDGMENTS}

The authors thank EPSRC for funding (EP/L019655/1).

\section{REFERENCES}

(1) James, S. L.; Adams, C. J.; Bolm, C.; Braga, D.; Collier, P.; Friscic, T.; Grepioni, F.; Harris, K. D. M.; Hyett, G.; Jones, W.; Krebs, A.; Mack, J.; Maini, L.; Orpen, A. G.; Parkin, I. P.; Shearouse, W. C.; Steed, J. W.; Waddell, D. C. Mechanochemistry: opportunities for new and cleaner synthesis. Chem. Soc. Rev. 2012, 41, 413-447.

(2) Do, J. L.; Friscic, T. Mechanochemistry: A Force of Synthesis. ACS Cent. Sci. 2017, 3, 13-19.

(3) Wang, G. W. Mechanochemical Organic Synthesis. Chem. Soc. Rev. 2013, 42, 7668-7700.

(4) Ferguson, M.; Giri, N.; Huang, X.; Apperley, D.; James, S. L. One-pot two-step mechanochemical synthesis: ligand and complex preparation without isolating intermediates. Green Chem. 2014, 16, 1374-1382.

(5) Bowmaker, G. A. Solvent-assisted mechanochemistry. Chem. Commun. 2013, 49, 334-348.

(6) Le Caër, G.; Delcroix, P.; Bégin-Colin, S.; Ziller, T. High energy ball-milling of alloys and compounds. Hyperfine Interact. 2002, $141,63-72$.

(7) Dhumal, R.; Kelly, A.; Coates, P.; York, P.; Paradkar, A. Cocrystalization and simultaneous agglomeration using hot melt extrusion. Pharm. Res. 2010, 27, 2725-2733.

(8) Kelly, A.; Coates, P.; York, P., Paradkar, A. Method and Product. WO Patent WO2010013035A1, February 4, 2010.

(9) Medina, C.; Daurio, D.; Nagapudi, K.; Alvarez-Nunez, F. J. Manufacture of pharmaceutical co-crystals using twin screw extrusion: A solvent-less and scalable process. J. Pharm. Sci. 2010, 99, 16931696.

(10) Ross, S. A.; Lamprou, D. A.; Douromis, D. Engineering and manufacturing of pharmaceutical co-crystals: a review of solvent-free manufacturing technologies. Chem. Commun. 2016, 52, 8772-8786.

(11) Crawford, D.; Casaban, J.; Haydon, R.; Giri, N.; McNally, T.; James, S. L. Synthesis by extrusion: continuous, large-scale preparation of MOFs using little or no solvent. Chem. Sci. 2015, 6, 1645-1649.

(12) Crawford, D. E.; Wright, L. A.; James, S. L.; Abbott, A. P. Efficient continuous synthesis of high purity deep eutectic solvents by twin screw extrusion. Chem. Commun. 2016, 52, 4215-4218.

(13) Crawford, D. E.; Miskimmin, C. K. G.; Albadarin, A. B.; Walker, G.; James, S. L. Organic synthesis by Twin Screw Extrusion (TSE): continuous, scalable and solvent-free. Green Chem. 2017, 19, 15071518.

(14) Crawford, D. E.; Casaban, J. Recent Developments in Mechanochemical Materials Synthesis by Extrusion. Adv. Mater. 2016, 28, 5747-5754.

(15) Mayoral, B.; Lopes, J.; McNally, T. Influence of Processing Parameters During Small-Scale Batch Melt Mixing on the Dispersion of MWCNTs in a Poly(propylene) Matrix. Macromol. Mater. Eng. 2014, 299, 609-621.

(16) Mitchell, C. A.; Bahr, J. L.; Arepalli, S.; Tour, J. M.; Krishnamoorti, R. Dispersion of Functionalized Carbon Nanotubes in Polystyrene. Macromolecules 2002, 35, 8825-8830.

(17) ThermoFisher Scientific. Presentation published online. http:// www.mcik.com/data/file/mcik/thermo/Rheomix_Internal_Mixers/ PI_Presentation_02_Drive_Mixer.pdf (accessed September 25, 2016).

(18) Wunsch, A.; Frendel, A. Evaluating the plasticization process of different soft-PVC samples; Case Study, Application Note LR59_09.01.09; Thermo Fisher Scientific: Karlsruhe, Germany, 2009.

(19) Kwong, C. Y.; Djurišić, A. B.; Choy, W. C. H.; Li, D.; Xie, M. H.; Chan, W. K.; Cheah, K. W.; Lai, P. T.; Chui, P. C. Efficiency and stability of different tris(8-hydroxyquinoline) aluminium (Alq3) derivatives in OLED applications. Mater. Sci. Eng., B 2005, 116, 75-81.

(20) Shahedi, Z.; Jafari, M. R.; Zolanvari, A. A. Synthesis of ZnQ2, $\mathrm{CaQ} 2$, and $\mathrm{CdQ} 2$ for application in OLED: optical, thermal, and electrical characterizations. J. Mater. Sci.: Mater. Electron. 2017, 28, $7313-7319$

(21) Ma, X.; Lim, G. K.; Harris, K. D. M.; Apperley, D. C.; Horton, P. N.; Hursthouse, M. B.; James, S. L. Efficient, Scalable, and Solvent-free Mechanochemical Synthesis of the OLED Material Alq3 ( $q=8$ Hydroxyquinolinate). Cryst. Growth Des. 2012, 12, 5869-5872.

(22) Chu, K. H.; Enright, R.; Wang, E. N. Structured surfaces for enhanced pool boiling heat transfer. Appl. Phys. Lett. 2012, 100, 241603-1-241603-4.

(23) Adamson, A. W.; Gast, A. P.; Physical Chemistry of Surfaces; Wiley-Interscience Publication: New York, 1967; p 282.

(24) Thomas, K. T.; Mathew, N. M.; Joseph, R. Studies on the Processability of Different Forms of Natural Rubber Using Torquerheometer. Int. J. Polym. Mater. 1998, 41, 207-214.

(25) Jerez, A.; Partal, P.; Martınez, I.; Gallegos, C.; Guerrero, A. Rheology and processing of gluten based bioplastics. Biochem. Eng. J. 2005, 26, 131-138.

(26) Paul, E. L.; Atiemo-Obeng, V. A.; Kresta, S. M. Handbook of Industrial Mixing: Science and Practice; John Wiley and Sons: Hoboken, NJ, 2004. 